\title{
The Efficacy of PBL Model in Pathology and Pathophysiology Teaching in China: A Meta-analysis
}

\author{
Jianguo $\mathrm{Hu}^{*}$, Xiaojing Hu, Zhengyue Shan, Rui Wang \\ School of Nursing, Anhui Sanlian University, Hefei, Anhui Province, CHINA.
}

\begin{abstract}
Purpose: To systematically evaluate the effect of PBL in Pathology and Pathophysiology teaching. Approach: CNKI, PubMed, WanFang Data, EMbase databases were electronically searched to collect randomized controlled trials (RCTs) of PBL model used in pathology and pathophysiology teaching in China from the database that has been constructed by September 20, 2019. Two researchers from the same research department independently screened and extracted literature materials for studying the evaluation bias risk and conducted a Meta-analysis using RevMan5.3 software. Findings: A total of 45 RCTs were enrolled, including 7,739 subjects. The Meta-analysis results indicate that PBL model in pathology and pathophysiology teaching is superior to traditional teaching model $(\mathrm{LBL})$ in terms of final examination score $[\mathrm{MD}=6.68,95 \% \mathrm{Cl}(5.29,8.06), P<0.00001]$, case analysis score $[\mathrm{MD}=4.15,95 \% \mathrm{Cl}(2.88,5.42), P<0.00001]$, increased learning interest $[R R=1.46,95 \% \mathrm{Cl}(1.28,1.66), P<0.00001]$, the ability to analyze and solve problems $[R R=2.21,95 \% \mathrm{Cl}(1.49,3.27), P<0.00001]$ and teamwork ability $[R R=1.7$, $95 \% \mathrm{Cl}(1.3,2.22), P<0.00001]$. Insights: The research results shown that $\mathrm{PBL}$ model can improve the teaching effect of Pathology and Pathophysiology, which, however, needs to be further verified by more high quality researches due to the limitation of literature quality in this research.

Key words: PBL, LBL, Pathology, Pathophysiology, Meta-analysis.
\end{abstract}

\section{INTRODUCTION}

China has a long and profound history of education. Confucius, a famous educator in China, advocated respecting teachers and valuing education in the Analects of Confucius more than 2,000 years ago. Therefore, it is a Chinese tradition to respect teachers. Such tradition is embodied in the fact that classroom teaching is teacher-centered where teachers have an absolute initiative in teachingwhilestudents arepassiveknowledge receiver." Therefore, "lecture-based learning" (LBL) has become the dominant teaching mode in China. However, with the rapid development of China's economy and society in recent years, the traditional teaching mode (LBL) finds it increasingly difficult to adapt to today's Chinese education. ${ }^{2}$ China's education administrators proposed to transform teacher-centered classroom teaching into student-centered one and emphasized that students' performances during the whole learning process should not be evaluated merely by final examination scores. Therefore, Chinese education, especially modern medical education, needs to be reformed and innovated. ${ }^{3}$ The diseases are becoming more and more complex, accompanied with an increasingly high incidence rate and mortality for malignant diseases, thus requiring medical colleges to cultivate high quality medical talents for clinical services. That's why medical colleges are advised to innovate their teaching mode to better adapt to modern medical education.

As a bridge between basic theory to clinical practice for medical students, Pathology and Pathophysiology are important basic
Submission Date: 25-01-2020; Revision Date: 14-04-2020; Accepted Date: 12-05-2020

DOI: 10.5530/ijper.54.3.104 Correspondence:

Mr. Jianguo Hu

School of Nursing, Anhui Sanlian University, 47 Hop on Road, Hefei, Anhui Province, CHINA.

Phone: +86-0-18956028889 E-mail: erhu1999@126.com

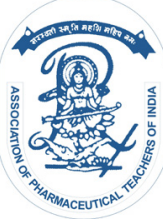

www.ijper.org 
courses in medical education. The traditional teaching mode (LBL) has shown some disadvantages, such as, it cannot stimulate students' interest in learning. In recent years, Chinese educators have gradually introduced an international teaching mode of problem-based learning (PBL), which was firstly introduced into medical education by Mike Barrows, a Professor of Neurology from Maast University in Canada. ${ }^{4}$ Such teaching mode is to adopt student-centered classroom teaching with Pathology teaching as an example. Practical clinical cases are adopted for classroom teaching so that students can give full play to their subjective initiative by consulting literature and materials and they are organized to discuss pathogenesis cases. Therefore, this teaching mode has become a hot spot in the reform of pathology and pathophysiology teaching in China's colleges and universities, but no sufficient theoretical basis is available for verifying its effect. This study systematically evaluates the effect of PBL and LBL in pathology and pathophysiology teaching by meta-analysis, which will provide reference for the reform in teaching.

\section{METHODS}

\section{Data sources and search strategy}

CNKI, PubMed, EMBASE and Wanfang databases were retrieved, only English and Chinese literature was searched and the retrieval strategy was designed. For example, keywords such as "problem-based learning" or "problem-based learning" and "pathology" or "pathophysiology" were used for search in PubMed database. In addition, any inconsistency was resolved by group discussion and consensus with the third party JH.

\section{Eligibility criteria}

The studies about such meta-analysis have to meet the following inclusion criteria: ${ }^{4}$ (1) A randomized controlled experiment of PBL and LBL has to be included; (2) The study objects are all subjects of pathophysiology or pathology in China, regardless of school system, learning form and race; (3) The results of this study are the final examination scores, case analysis scores, students' interest in learning, their ability to analyze and solve problems and team cooperation ability; (4) The study is published in both Chinese or English. Additionally, incomplete data, repeated publication, reports and experimental courses that are not about PBL teaching mode or LBL teaching mode and nonChinese and English literature are excluded.

\section{Data extraction}

The eligible texts were selected by two independent research institutes [ZS and RW]. The third party were involved in consultation and would make a final decision $[\mathrm{JH}]$ in case of disagreement.

For the purpose of this study, two independent researchers [XH and RW] extracted the following information from eligible studies: (1) The first author's name and year of publication; (2) Research object's unit, major, number of participants and educational level; (3) Specific details of intervention and control measures; (4) Elements for bias risk assessment; (5) Outcome indicators: final examination scores, case analysis scores, students' interest in learning, their ability to solve and analyze problems and team cooperation ability. All the extracted data were saved in Excel.

\section{Quality evaluation}

Two investigators [xhandzs] independently evaluated the bias risk according to the RCTs risk bias tool recommended in Cochrane manual 5.1.0 and crosschecked the results.

\section{Statistical analysis}

Revman 5.3 software provided by Cochrane website was used for meta-analysis. The mean deviation (MD) and the risk ratio (RR) were used as the effect analysis statistics for two classification variables, both of which were $95 \%$ CI. $\chi^{2}$ test (test standard a $=0.1$ ) was used to analyze the heterogeneity among the included results and then combined with $\mathrm{I}^{2}$ to judge the heterogeneity. The fixed effect model will be used if there is no heterogeneity among results. Otherwise, random effect model will be used after obvious heterogeneity is excluded. The Meta-analysis standard is that a $=0.05$. Significant heterogeneity was analyzed by subgroup analysis, sensitivity analysis or descriptive analysis.

\section{RESULTS}

\section{Literature retrieval and qualified research}

Through literature search, 6,469 related articles were retrieved from CNKI $(2,469)$, PubMed (72), EMBASE (2), Wanfang $(3,926)$, among which 4,432 articles were deleted and 2,037 related articles were collected. The abstracts of these articles were reviewed to evaluate their eligibility. A total of 1,963 articles did not meet the criteria for inclusion, so they were excluded. In addition, 


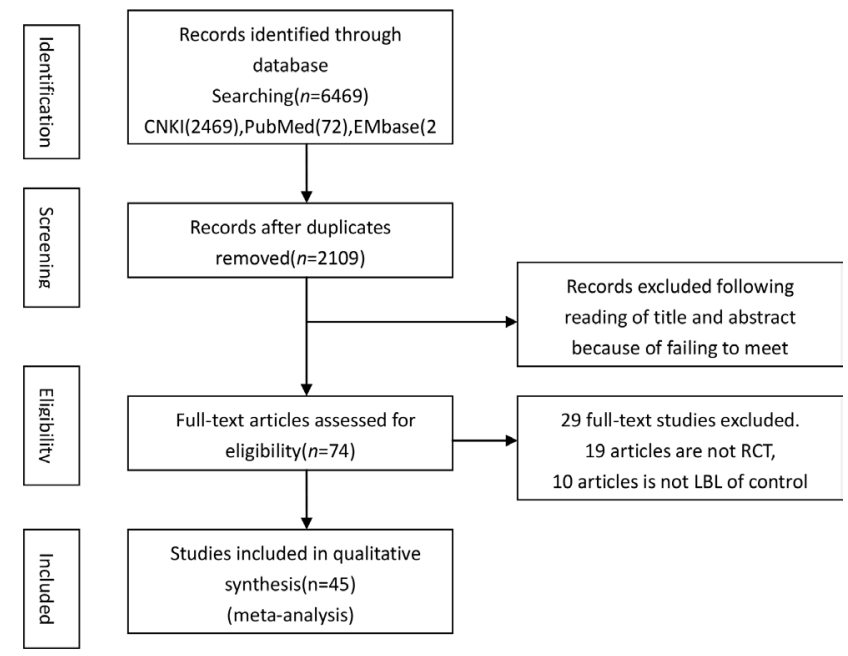

Figure 1: Flow chart of study selection, which indicate the process by which relevant studies were retrieved from databases, assessed, selected and excluded. Preferred reporting items for systematic review and meta-analyses diagram for study search.

the full text of 74 articles was reviewed, of which 29 articles were excluded. Finally, 45 articles that met the criteria for inclusion were included in the final metaanalysis (Figure 1).

\section{Characteristics of the articles}

The characteristics and bias risk of the 45 eligible studies are shown in Table 1 and Table 2, respectively.

\section{Final examination scores}

A total of 37 RCTs $^{6-12,14-21,23-26,28,30-42,44,46-49}$ were included in the meta analysis of two groups of data using the random effect model: PBL group was superior to LBL group, with a statistically significant difference [MD = 6.68, 95\% CI (5.29,8.06), $P<0.00001$ ] (Figure 2).

\section{Case analysis scores}

A total of 12 RCTs $^{6,9,11,15,18-20,29,33,38,39,47}$ were included in the meta analysis of two groups of data using the random effect model: PBL group was superior to LBL group, with statistically significant difference $[\mathrm{MD}=$ 4.15, 95\% CI $(2.88,5.42), P<0.00001$ ] (Figure 3).

\section{Stimulating students' interest in learning}

A total of 14 RCTs $^{5,6,13,14,17,21-24,27,31,43,45,47,48}$ were included in the meta analysis of two groups of data using the random effect model: PBL group was superior to LBL group, with statistically significant difference $[\mathrm{RR}=$ 1.46, 95\% CI $(1.28,1.66), P<0.00001$ ] (Figure 4).

\section{Students' ability to solve and analyze problems}

A total of $11 \mathrm{RCTs}^{6,13,14,17,22-24,27,43,47,48}$ were included in the meta analysis of two groups of data using the

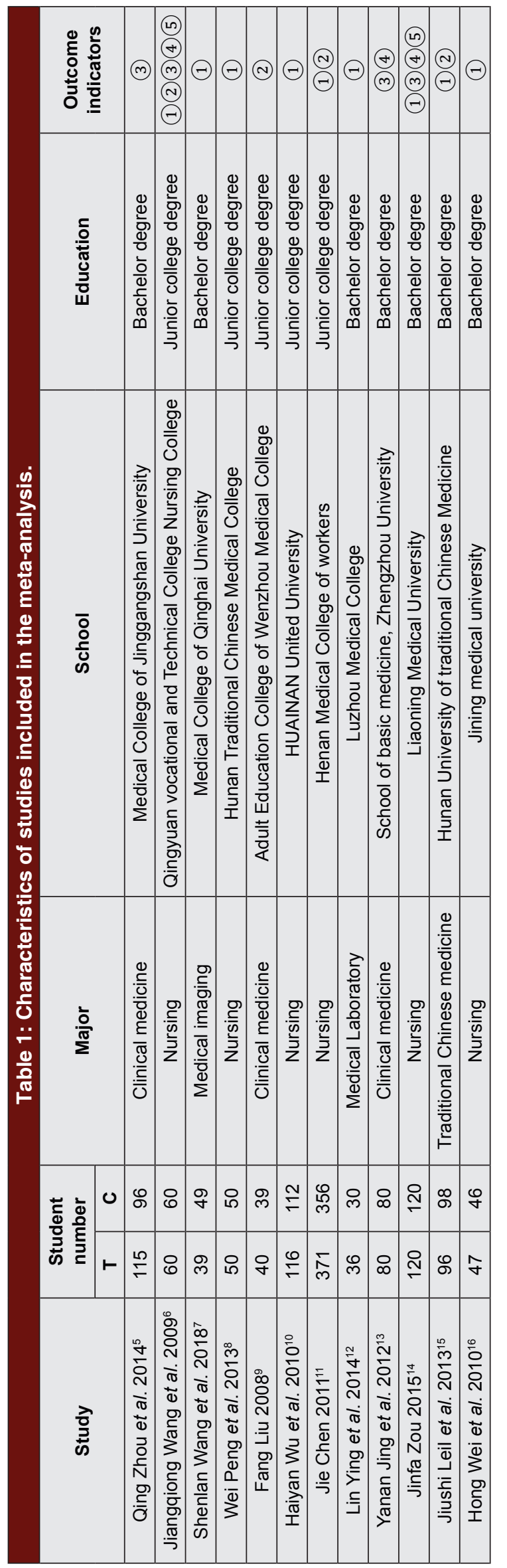




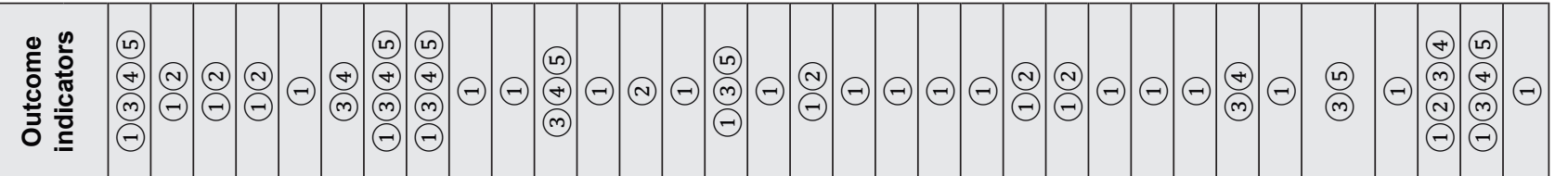

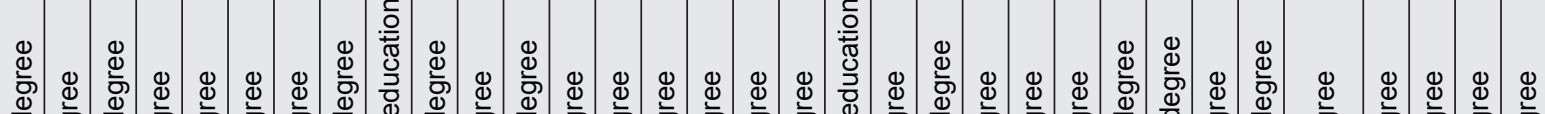

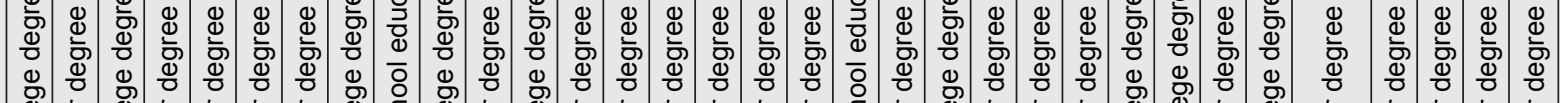

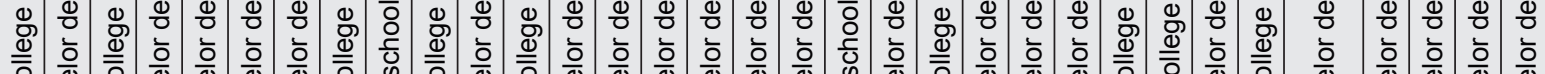

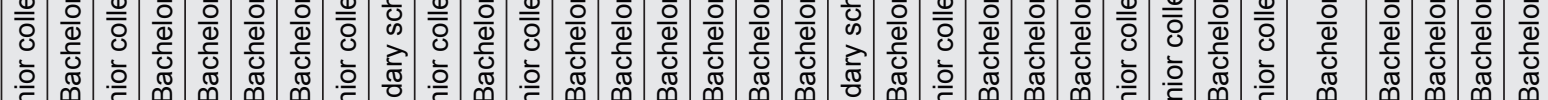

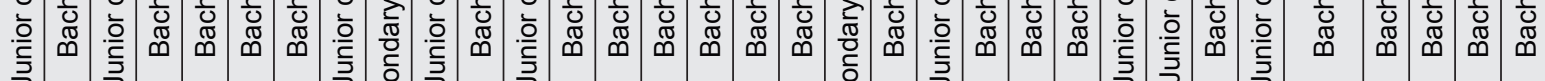

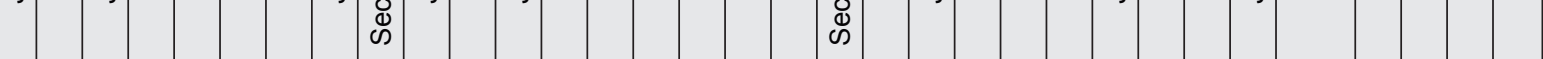

IEt

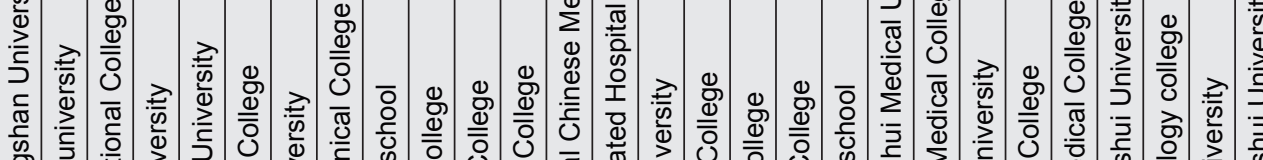

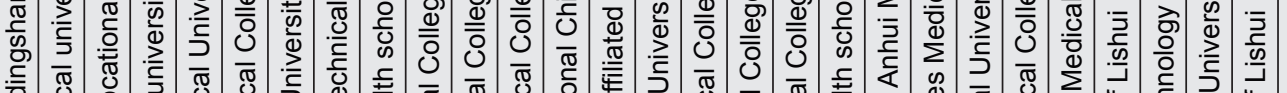

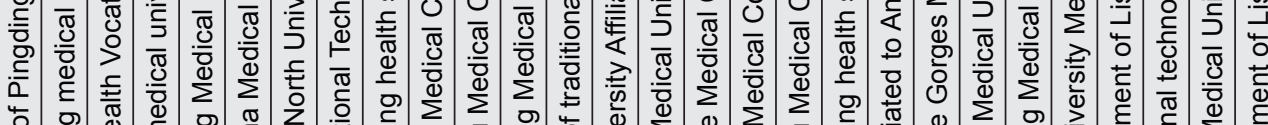

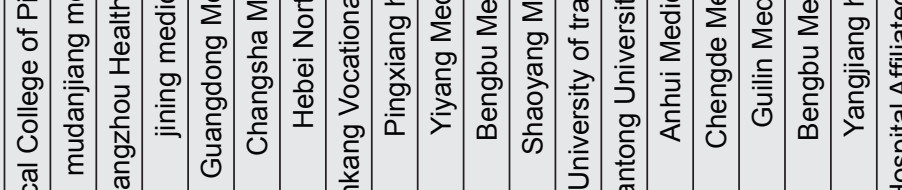

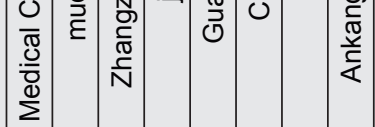

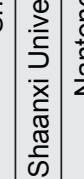

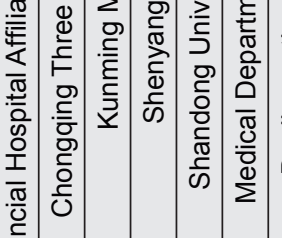

竞

(2)

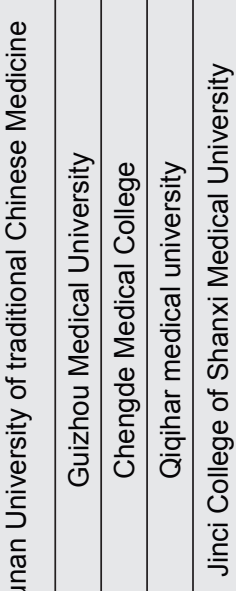

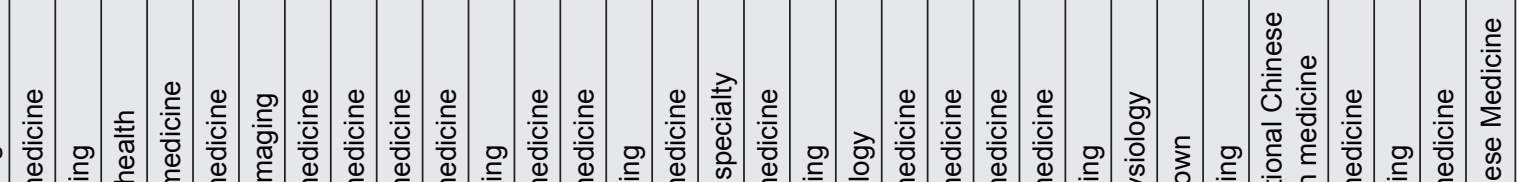

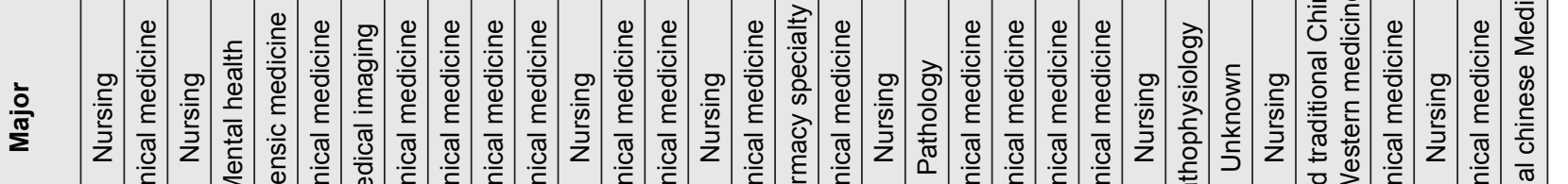

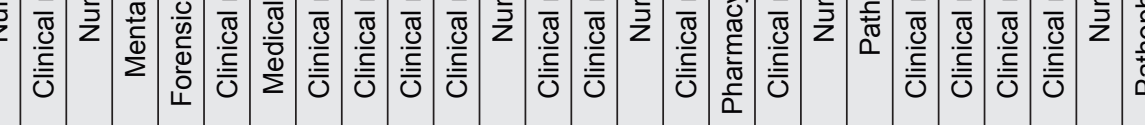

蒙 क 至

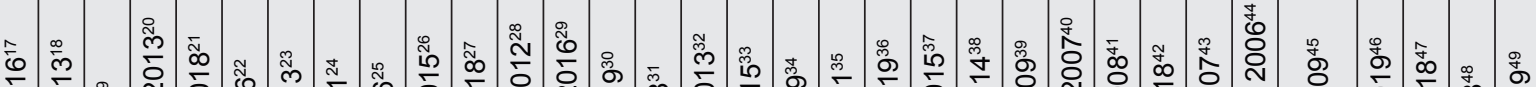

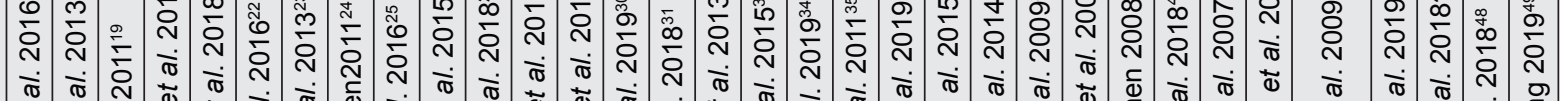

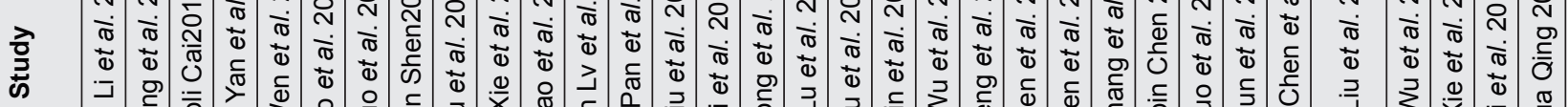

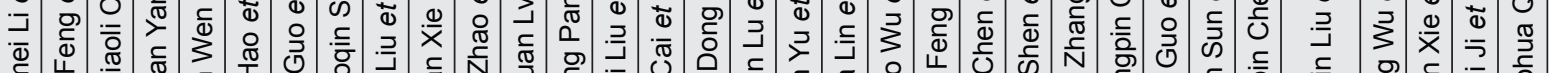

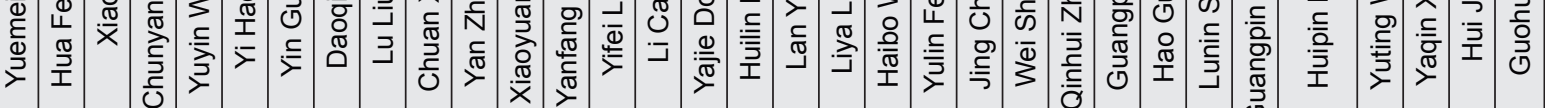

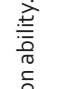
第 
Table 2: Bias risk assessment results included in the study.

\begin{tabular}{|c|c|c|c|c|c|c|}
\hline Study & RCTs & $\begin{array}{l}\text { Allocation } \\
\text { concealment }\end{array}$ & $\begin{array}{l}\text { Blind } \\
\text { method }\end{array}$ & $\begin{array}{c}\text { Data } \\
\text { integrity }\end{array}$ & $\begin{array}{c}\text { Selective } \\
\text { reporting of } \\
\text { research results }\end{array}$ & $\begin{array}{c}\text { Other } \\
\text { sources } \\
\text { of bias }\end{array}$ \\
\hline Qing Zhou et al. $2014^{5}$ & unclear & nothing & no & complete & nothing & nothing \\
\hline Jiangqiong Wang et al. $2009^{6}$ & unclear & nothing & no & complete & nothing & nothing \\
\hline Shenlan Wang et al. $2018^{7}$ & unclear & nothing & no & complete & nothing & nothing \\
\hline Wei Peng et al. $2013^{8}$ & unclear & nothing & no & complete & nothing & nothing \\
\hline Fang Liu $2008^{9}$ & unclear & nothing & no & complete & nothing & nothing \\
\hline Haiyan Wu et al. $2010^{10}$ & unclear & nothing & no & complete & nothing & nothing \\
\hline Jie Chen $2011^{11}$ & unclear & nothing & no & complete & nothing & nothing \\
\hline Lin YING et al. $2014^{12}$ & block randomization & nothing & no & complete & nothing & nothing \\
\hline Yanan Jing et al. $2012^{13}$ & unclear & nothing & no & complete & nothing & nothing \\
\hline Jinfa Zou $2015^{14}$ & unclear & nothing & no & complete & nothing & nothing \\
\hline Jiushi Lei et al. $2013^{15}$ & unclear & nothing & no & complete & nothing & nothing \\
\hline Hong Wei et al. $2010^{16}$ & unclear & nothing & no & complete & nothing & nothing \\
\hline Yuemei Li et al. $2016^{17}$ & unclear & nothing & no & complete & nothing & nothing \\
\hline Hua Feng et al. $2013^{18}$ & unclear & nothing & no & complete & nothing & nothing \\
\hline Xiaoli Cai $2011^{19}$ & unclear & nothing & no & complete & nothing & nothing \\
\hline Chunyan YAN et al. $2013^{20}$ & unclear & nothing & no & complete & nothing & nothing \\
\hline Yuyin Wen et al. $2018^{21}$ & unclear & nothing & no & complete & nothing & nothing \\
\hline Yi Hao et al. $2016^{22}$ & unclear & nothing & no & complete & nothing & nothing \\
\hline Yin Guo et al. $2013^{23}$ & unclear & nothing & no & complete & nothing & nothing \\
\hline Daoqin Shen $2011^{24}$ & unclear & nothing & no & complete & nothing & nothing \\
\hline Lu Liu et al. $2016^{25}$ & unclear & nothing & no & complete & nothing & nothing \\
\hline Chuan Xie et al. $2015^{26}$ & unclear & nothing & no & complete & nothing & nothing \\
\hline Yan Zhao et al. $2018^{27}$ & unclear & nothing & no & complete & nothing & nothing \\
\hline Xiaoyuan Lv et al. $2012^{28}$ & unclear & nothing & no & complete & nothing & nothing \\
\hline Yanfang Pan et al. $2016^{29}$ & unclear & nothing & no & complete & nothing & nothing \\
\hline Yifei Liu et al. $2019^{30}$ & unclear & nothing & no & complete & nothing & nothing \\
\hline Li Cai et al. $2018^{31}$ & random sampling & nothing & no & complete & nothing & nothing \\
\hline Yajie Dong et al. $2013^{32}$ & unclear & nothing & no & complete & nothing & nothing \\
\hline Huilin Lu et al. $2015^{33}$ & unclear & nothing & no & complete & nothing & nothing \\
\hline Lan Yu et al. $2019^{34}$ & unclear & nothing & no & complete & nothing & nothing \\
\hline Liya Lin et al. $2011^{35}$ & unclear & nothing & no & complete & nothing & nothing \\
\hline Haibo Wu et al. $2019^{36}$ & unclear & nothing & no & complete & nothing & nothing \\
\hline Yulin Feng et al. $2015^{37}$ & unclear & nothing & no & complete & nothing & nothing \\
\hline Jing Chen et al. $2014^{38}$ & unclear & nothing & no & complete & nothing & nothing \\
\hline Wei Shen et al. $2009^{39}$ & unclear & nothing & no & complete & nothing & nothing \\
\hline Qinhui Zhang et al. $2007^{40}$ & unclear & nothing & no & complete & nothing & nothing \\
\hline Guangpin Chen $2008^{41}$ & unclear & nothing & no & complete & nothing & nothing \\
\hline Hao Guo et al. $2018^{42}$ & unclear & nothing & no & complete & nothing & nothing \\
\hline Lunin Sun et al. $2007^{43}$ & unclear & nothing & no & complete & nothing & nothing \\
\hline Guangpin Chen et al. $2006^{44}$ & unclear & nothing & no & complete & nothing & nothing \\
\hline Huipin Liu et al. $2009^{45}$ & unclear & nothing & no & complete & nothing & nothing \\
\hline Yuting Wu et al. $2019^{46}$ & unclear & nothing & no & complete & nothing & nothing \\
\hline Yaqin Xie et al. $2018^{47}$ & unclear & nothing & no & complete & nothing & nothing \\
\hline Hui Ji et al. $2018^{48}$ & unclear & nothing & no & complete & nothing & nothing \\
\hline Guohua Qing $2019^{49}$ & unclear & nothing & no & complete & nothing & nothing \\
\hline
\end{tabular}




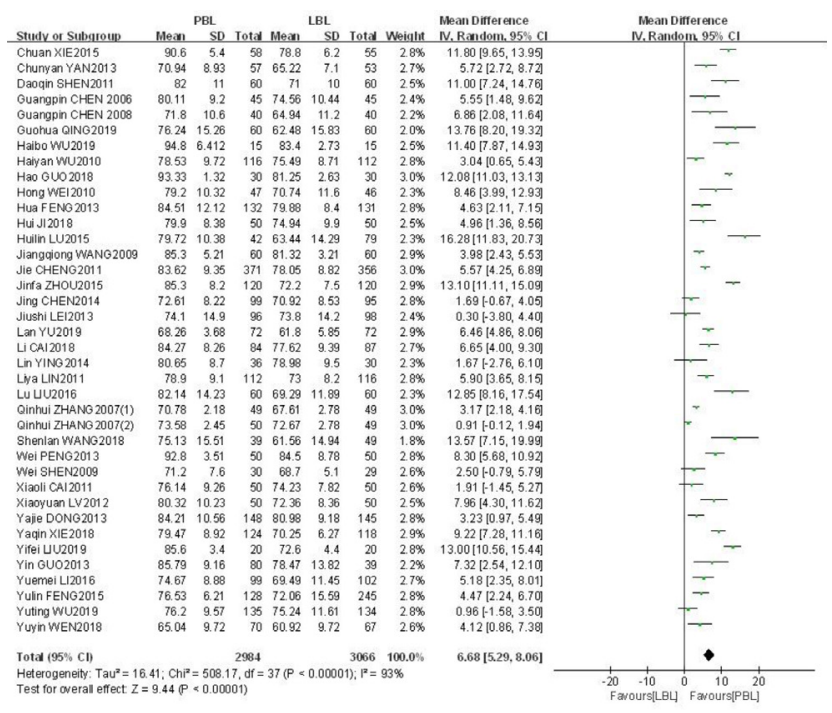

Figure 2: Meta-analysis of the final examination scores of PBL group and LBL group.

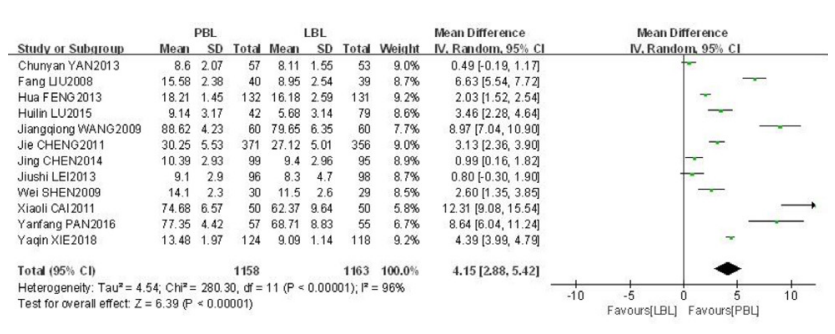

Figure 3: Meta-analysis of the case analysis scores of PBL group and LBL group.

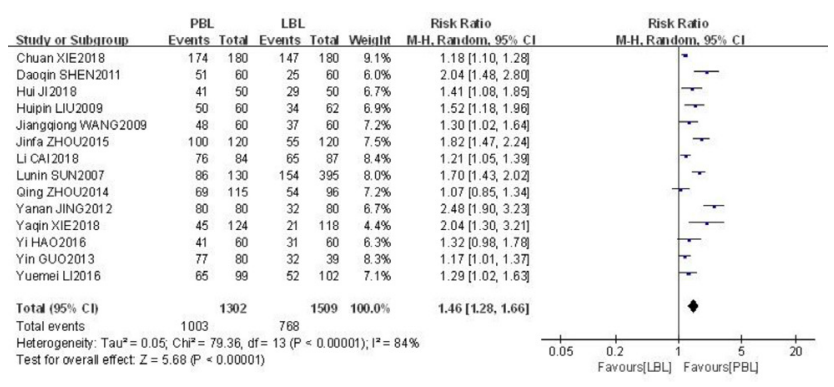

Figure 4: Meta-analysis of students' interest in learning of PBL group and LBL group.

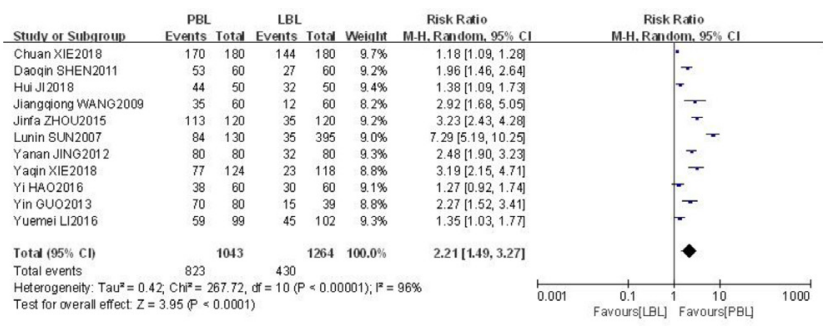

Figure 5: Meta-analysis of students' ability to solve and analyze problems of PBL group and LBL group.

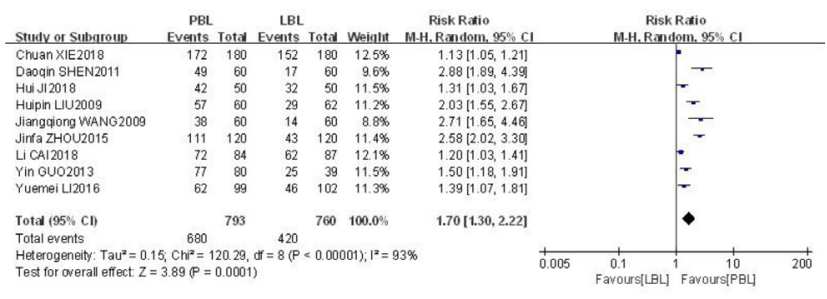

Figure 6: Meta-analysis of students' team cooperation ability of PBL group and LBL group.

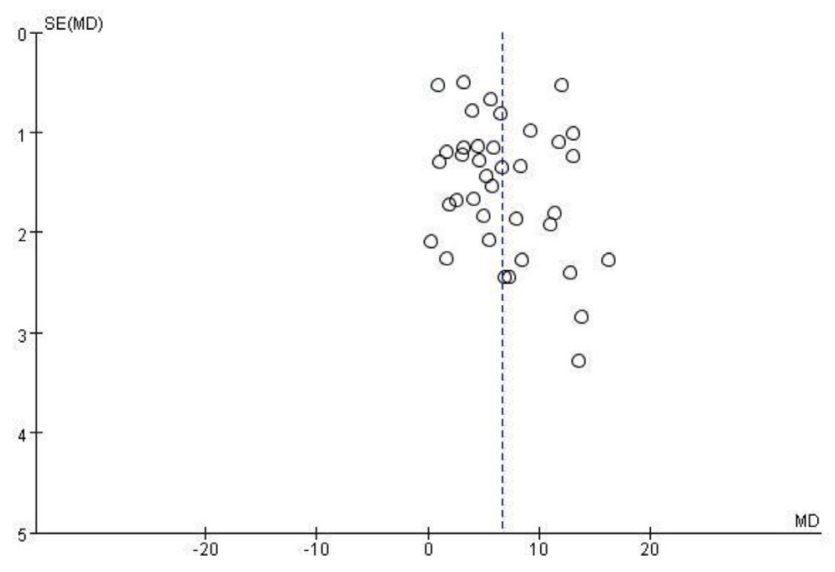

Figure 7: Funnel chart of final exam scores.

random effect model: PBL group was superior to LBL group, with a statistically significant difference [RR $=2.21,95 \%$ CI $(1.49,3.27), P<0.00001]$ (Figure 5).

\section{Students' team cooperation ability}

A total of 9 RCTs ${ }^{6,14,17,23,24,27,31,45,48}$ were included in the meta analysis of two groups of data using the random effect model: PBL group was superior to LBL group, with a statistically significant difference $[R R=1.7,95 \%$ CI (1.3,2.22), $P<0.00001$ ] (Figure 6).

\section{Bias analysis}

According to the final examination results, a funnel chart was drawn to detect publication bias. The distribution of each research point was basically symmetrical, indicating that the possibility of publication bias was small (Figure 7).

\section{DISCUSSION}

The outcome indicators included in this study exhibit great heterogeneity, which is possibly because of the difference in educational level, educational background and specialty of each research object, educational resource uneven quality of the included literature and available heterogeneity sources. Therefore, it is difficult to conduct subgroup analysis. PBL teaching mode was 
only used in some chapters instead of the whole process of PBL teaching, so the accuracy of final examination results could be somewhat affected. According to the characteristics of teaching, students know their own grouping at the very beginning, so it is difficult to implement blind method and distribution concealment, thus possibly resulting in bias.

By comparing the application effect of PBL and LBL in pathology and pathophysiology teaching in this study, the experimental group students can better be involved in classroom teaching, thus obviously stimulating their interest in learning. Furthermore, students can also participate in discussing problems in groups so they ability to analyze and solve problems and team cooperation will be enhanced. The result of final examination are better than that of LBL group, indicating that students have solid basic theoretical knowledge. The result of case analysis are better than that of LBL group, which indicates that students can skillfully combine theory with clinical practice. PBL teaching mode has developed students' comprehensive ability for clinical service, so it is obviously superior to LBL teaching mode and can be widely applied.

\section{ACKNOWLEDGEMENT}

This work was supported by Research Funding from the Key Research Project of Teaching Quality Engineering of Anhui Sanlian University (No.17zlgc044) and Teaching Quality Engineering Project of Anhui Provincial Department of Education (No.2019jyxm0515)

\section{CONFLICT OF INTEREST}

The authors of this paper declare no conflicts of interest.

\section{ABBREVIATIONS}

PBL: problem-based learning; LBL: lecture-based learning; RCTs: Randomized controlled trial.

\section{REFERENCES}

1. Zhili X, Jingxian Y. Application of problem based learning and case based study in clinical pharmacotherapy teaching. West China Medical Journal. 2011;26(1):114-6.

2. Qining $\mathrm{F}$, Hua $\mathrm{H}$, Wenjiao $\mathrm{T}$, et al. The role of student subjectivity in the professionalism education of medical students. Basic and Clinical Medicine. 2012;32(12):1371-3.

3. Yongwei Z. The methodology of university teaching reform. Journal of National Academy of Education Administration. 2012;(1):43-7.

4. Jingsi $D$, Bingjie $L$, Dan $L$, et al. The efficacy and satisfaction of PBL model in clinical oncology teaching in China: A meta-analysis. Chinese Journal of Evidence-based Medicine. 2019;19(8):968-75.

5. Qing Z, Yuhui H, Yushan $\mathrm{H}$, et al. Practice and exploration of PBL teaching method in bilingual course of pathophysiology. Chongqing Medical. 2014;43(10):1275-8
6. Jiangqiong $W$, Zhisu P. Application of PBL approach in pathology teaching of nursing disciplin. Chin J Nurs Educ. 2009;6(1):18-20.

7. Shenglan W, Xuefeng C, Huiqi L, et al. Application of PBL and LBL teaching model in pathophysiology teaching. Basic Medical Education. 2018;20(2): 89-92.

8. Wei P, Qisheng L, Xiaohong X, et al. Preliminary evaluation on comprehensive teaching mode in pathobiology for higher vocational education. Guiding Journal of Traditional Chinese Medicine and Pharmacy. 2013;19(5):130-1.

9. Fang L. Experiment and reflection on PBL teaching in pathology of adult education. Zhejiang Medical Education. 2008;7(2):22-4.

10. Haiyan $\mathrm{W}$, Hao L, Hyo $\mathrm{H}$, et al. Application of PBL teaching method in the pathoanatomy of nursing specialty in Higher Vocational College. Modern Journal of Integrated Traditional Chinese and Western Medicine. 2010;19(5):643-4

11. Jie C. Application of Problem-based learning in pathophysiology teaching of nursing science. Journal of Henan Medical College of Workers. 2011;23(3):332-4.

12. Ling $\mathrm{Y}$, Zhonghua $\mathrm{T}$, Guijun $\mathrm{P}$, et al. The research of zhe teaching inspection method about PBL teaching moder in ultrastructural pathology class. The Science Education Article Coiiects. 2014;(291):84-85.

13. Yanan J, Youtian H, Jimin Z, et al. Application of PBL teaching mode in experimental teaching of pathophysiology. China Higher Medical Education. 2012;(7):1-2,18

14. Jinfa Z. Preliminary application of PBL teaching mode in pathophysiology teaching. Journal of Liaoning Medical University. 2015;13(4):47-9, 52.

15. Jiushi L, Qun T, Li C, et al. Application and discussion of PBL teaching mode in university of TCM pathology teaching of undergraduate course. China Higher Medical Education. 2013;(3):100-2.

16. Hong W, Chunyan Y, Xiaogang J, et al. Application of multimedia combined with Problem-based learning teaching method in pathology teaching of nursing discipline. Chin J Nurs Educ. 2010;7(7):310-1.

17. Yuemei L, Xinhua Z. Application of PBL combined with flipped classroom teaching mode in pathology teaching. China Modern Medicine. 2016;23(23):165-7.

18. Hua F, Pei C, Chunhui R, et al. The application of integration of PBL with TBL teaching methods in the case study teaching of pathophysiology. Soft Science of Health. 2013;27(11):690-2.

19. Xiaoli C. Study on the teaching method of pathophysiology combining PBL and EBM. Journal of Qiqihar University of Medical. 2011;32(16):2636-7.

20. Yan C, Wei H. Application of PBL in traditional pathology teaching. Health Vocational Education. 2013;31(4):112-3.

21. Yuying $W$, Jin $C$, Mingyong $L$, et al. Study on the promoting effect of TBL combined with $\mathrm{PBL}$ teaching on College Students' pathology course learning. Science and Technology Wind. 2018;(7):3, 66.

22. Yi H, Ping Y, Qian G, et al. Application of TBL and PBL combined teaching method in pathology teaching. Basic Medical Forum. 2016;20(1):111-2.

23. Ying G, Chunting J, Guohui Z, et al. Study on teaching pathology with PBL teaching model in promoting multidisciplinary fusion. Medical Research and Education. 2013;30(4):97-100.

24. Daoqing S. Application of PBL in pathology teaching. Hebei Medicine Journal. 2011;33(17):2687.

25. Lu L, Yuting W. Application of PBL and LBL dual track teaching mode in pathology teaching of secondary vocational school. Vocational Education. 2016;(12):121.

26. Chuan X, Yuanyue L, Ju H, et al. Application of PBL teaching mode in pathology teaching of higher vocational colleges. Contemporary Medicine. 2015;21(27):163-4.

27. Yan Z, Xin J, Nan L, et al. The application of multi-modal teaching reform in pathology. Journal of Baotou Medical College. 2018;34(6):104-6.

28. Xiaoyuan L, Huaxiu W, Shaona Z. Model of pathology teaching for advanced nursing profession. Basic Medical Forum. 2012;16(19):2563-4.

29. Yanfang P, Yan F, Xiaoping Y. Effect evaluation of comprehensive reform of pathology course based on PBL. Education Teaching Forum. 2016;(14):87-8.

30. Yifei L, Haosheng N, Jia F, et al. PBL teaching practice and thinking of medical students' clinical pathological diagnosis thinking based on barrows model. Med J Communication. 2019;33(3):316-8. 
31. Li C, Gang M, Xiangyang H, et al. Application of PBL based "split class" teaching mode in pathology teaching. Journal of Mudanjiang Medical University. 2018;39(5):139-42.

32. Yajie D, Kaifeng L, Fanxing $M$, et al. Research on preliminary applied of pathophysiology teaching reform based on PBL teaching mode. China Higher Medical Education. 2013;(2):60-2.

33. Huiling L, Guangying $Q$, Zhen W, et al. Using the PBL based case-discussion method to teach pathophysiology. China Higher Medical Education. 2015;(5):105-6.

34. Lan Y, Bingqin G, Lei Z, et al. study on the application of flipped classroom model based on PBL in teaching of pathology under the background of medicine certification. Journal of Qiqihar Medical University. 2019;40(4):488-90.

35. Liya L, Tingting L. PBL method in pathology teaching application experience. Journal of Anhui Vocational and Technical College of Health. 2011;10(5):91-2.

36. Haibo W, Jun D. Application of real-time pathology remote consultation system combined with PBL and $\mathrm{CBL}$ in clinical pathology teaching. The Science Education Artical Collects. 2019;(458):112-4.

37. Yuling $\mathrm{F}$, Jie $\mathrm{C}$, Ling $\mathrm{H}$, et al. Exploring the application of PBL, CPC and LBL in the teaching practice of pathology. Chongqing Medical. 2015;44(9):1284-6.

38. Jing $C$, Shuqing $L$, Ying $Z$, et al. Application of $P B L$ teaching method based on medical record in pathophysiology teaching. Chongqing Medical. 2014;43(20):2677-8.

39. Wei S, Lu S, Liyan Z, et al. Application of PBL teaching method centered on case discussion in pathophysiology teaching. Journal of Shanxi Medical University. 2009;11(3):270-1.
40. Qinghui Z, Jianxin H, Gengyin Z, et al. Clinical problem-based learning approach in systemic pathology Teaching reform. Researches in Medical Education. 2007;6(4):308-9, 26.

41. Guangping Chen. On application of PBL combined LBL in pathology teaching Journal of Lishui University. 2008;30(2):107-9.

42. Hao G, Ting Z. Application of problem-based learning in pathophysiology teaching. Cardiovascular Disease Journal of Integrated Traditional Chinese and Western Medicine. 2018;6(3):184.

43. Luning S, Haipeng Z, Chenghai Z, et al. Application of problem-based learning in pathophysiology teaching. Chinese Journal of Pathophysiology. 2007;23(3):622-4

44. Guangping $C$, Ninghai $Y$, Wuxing $C$. Research and practice of problem-based learning in pathology teaching. Medical Theory and Practice. 2006;19(9):114-5.

45. Huiping L, Jinwen G, Guomin Z, et al. Discussion of PBL teaching pattern in pathophysiology in traditional Chinese medicine. China Medical Herald. 2009;6(36):129-30.

46. Yuting $\mathrm{W}$, Wenxiu $\mathrm{Y}$, Yanjie L, et al. Application of CPL and PBL in pathology teaching reform. Health Vocational Education. 2019;37(14):54-5.

47. Yaqin $X$, Juan $Z$, Quanxin $Y$, et al. Application of $L B L+C B L+P B L$ teaching mode in the teaching practice of pathophysiology of four-year nursing major. China Higher Medical Education. 2018;(2):78-9.

48. Hui J, Wei XLJ, et al. Evaluation of the application of $L B L$ and PBL in pathophysiology teaching. Continuing Medical Education. 2018;32(11):32-3.

49. Guohua Q. Application of PBL + LBL model in pathophysiology teaching Modern Salt Chemical Industry. 2019;(3):128-9.

\section{PICTORIAL ABSTRACT}

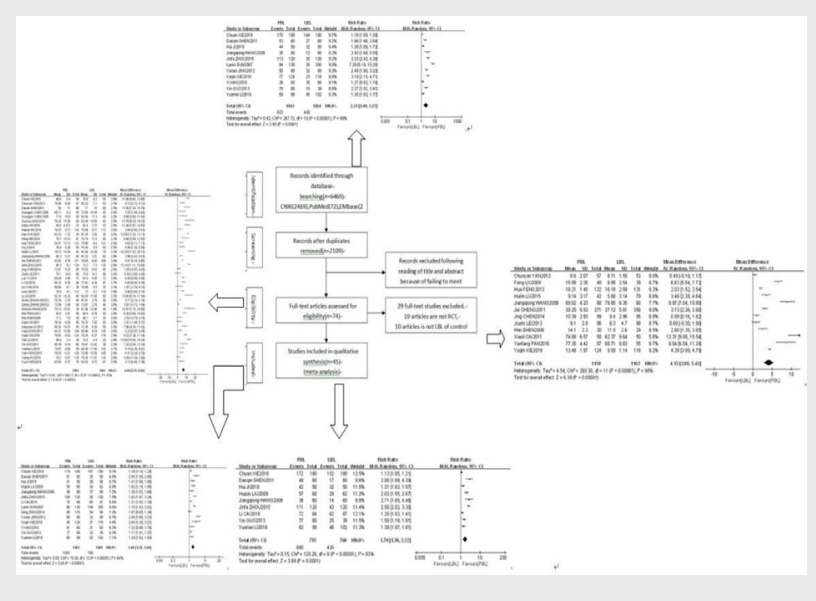

About Authors

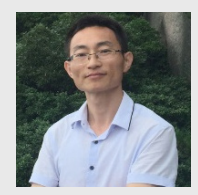

Jianguo Hu: School of Nursing, Anhui Sanlian University, Master's degree, mainly engaged in basic Medical Teaching and Research.

\section{SUMMARY}

China has a long and profound history of education. Respecting teachers is an excellent Chinese tradition. Teacher-centered classroom teaching (LBL) has been adopted in China for a long time. As modern western medicine makes its presence in China, traditional teaching mode finds it increasingly difficult to adapt to the requirements of modern western medicine. As the society develops and people's living standards improve, diseases is becoming more and more complex, accompanied with a high incidence rate and mortality for malignant diseases. Therefore, medical colleges and universities are required to cultivate highquality medical talents for clinical services, so they are advised to innovate their teaching mode to adapt to modern medical education. In recent years, PBL mode has been gradually applied in classroom teaching. The results of PBL mode and LBL mode in the final examination, case analysis, stimulating learning interest, the ability to analyze and solve problems and team cooperation in pathology and pathophysiology teaching are evaluated and they indicate that PBL mode is better than LBL mode. 
Xiaojing Hu: School of Nursing, Anhui Sanlian University, Master's degree, mainly engaged in Pharmaceutical Teaching and Research.

Zhengyue Shan: School of Nursing, Anhui Sanlian University, Master's degree, mainly engaged in Educational Research.

Rui Wang: School of Nursing, Anhui Sanlian University, Master's degree, mainly engaged in Educational Research.

Cite this article: Hu J, Hu X, Shan Z, wang R. The Efficacy of PBL Model in Pathology and Pathophysiology Teaching in China: A Meta-analysis. Indian J of Pharmaceutical Education and Research. 2020;54(3):556-64. 